\title{
Effects of aging in Masters swimmers: 40-year review and suggestions for optimal health benefits
}

REVIEW

\author{
Robert T Rubin ${ }^{1,2}$ \\ Richard H Rahe ${ }^{3}$ \\ 'Department of Psychiatry and \\ Biobehavioral Sciences, David Geffen \\ School of Medicine at UCLA, Los \\ Angeles, CA, USA; ${ }^{2}$ UCLA Bruin \\ Masters Swim Club, CA, USA; \\ ${ }^{3}$ Department of Psychiatry, Portland \\ VA Hospital Community-Based \\ Outpatient Center, Salem, OR, USA
}

Correspondence: Robert T Rubin Department of Psychiatry,VA Greater Los Angeles Healthcare System, Bldg 500 Room 6428, I I 30 I Wilshire Blvd, Los Angeles, CA 90073 USA

Tel + I-3I 0-268-3319

Fax +I-3I 0-268-4377

Email robert.rubin@va.gov
This article was published in the following Dove Press journal:

Open Access Journal of Sports Medicine

8 April 2010

Number of times this article has been viewed

\begin{abstract}
The Masters Swimming Program is over 40 years old and has achieved international status, with thousands of participants competing in five-year age categories between 18 and 99 . Early studies of Masters swimmers by age groups found an increase in times for most events of about $1 \%$ per year, and later studies showed a significant correlation with the age-associated decline in maximal oxygen uptake. As larger sample sizes have become available, the age-related decline in performance among national champion Masters swimmers, both men and women, and for both short and longer swims, has been shown to be linear at about $0.6 \%$ per year up to age 70. Beyond age 70, the age-related decline accelerates exponentially for both men and women, with considerably more variability than in younger age groups. Several factors may be related to the accelerated performance decline beyond the of age 70, including accelerated physiological aging, chronic physical disabilities, acute illnesses requiring relatively lengthy recovery, effects of multiple medications, and social issues such as transportation problems, all of which can lead to increasing difficulty in maintaining a regular workout schedule. Masters Swimming is a "user-friendly" aerobic sport, imposing little excess strain, and thus is particularly suitable for the elderly. Masters coaches are gaining increasing experience with the over-70 age groups, tailoring workouts to accommodate their need for longer warm-up periods, longer rest periods between swimming sets, less overall distance, less emphasis on "breath control", and more time between workouts. With these accommodations, the motivation of elderly Masters swimmers
\end{abstract} to compete remains strong, and their ranks should continue to increase.

Keywords: masters swimming, aging, physiological functional capacity

\section{Early history}

In the late 1960s, Ransom J Arthur, MD, a US Navy Medical Officer and coach of the 11 th Naval District (San Diego, CA) swim team, proposed the creation of a United States Masters Swim Program organized along the lines of the existing Masters Track and Field Program. Masters Track and Field was open to adults 40 years of age and older, competing in 10-year age groups. Dr Arthur emphasized that competitive swimmers usually retired in their mid-20s, and a Masters program would encourage both ex-competitive swimmers and beginners to improve and maintain their fitness.

John Spannuth, director of the Amarillo (Texas) Aquatic Club, partnered with Dr Arthur and organized the first national Masters Swimming competition in Amarillo in May 1970. Seventy-eight men and women, aged 25 to 60, including the authors of this review, participated. The atmosphere was one of fun, sportsmanship, and healthy rivalry. Stott ${ }^{1}$ quotes a 16 -year-old volunteer at the meet as saying, 
"I can't believe these old people are racing. My parents never worked out. It was foreign and strange." In 1972 , Masters Swimming was placed under the Amateur Athletic Union, and the first National AAU Masters (Short Course) Swimming Championships were held in San Mateo, California. Participants now numbered 325, and ages ranged from 25 to 80 years. In 1974, the first International Masters Swim Competitions were held in Auckland, New Zealand and Sydney, Australia. Currently, there are over 42,000 registered US Masters swimmers, and there were more than 1500 registrants for the 2009 Short Course National Championships. $^{2}$

The first scientific publication on Masters Swimming reported on biological measures taken pre- and post-competition in 15 male swimmers, aged 28 to 56 years, at the 1970 Amarillo meet. ${ }^{3}$ Several swimmers had never competed previously, but most had participated in training programs. Following their competitive swims, systolic and diastolic blood pressure dropped, serum uric acid and cholesterol concentrations increased, and one subject showed a minor electrocardiographic change. Because no troublesome cardiovascular problems occurred overall, the conclusion was that "swim competition was medically safe for the well-conditioned older swimmer."3

\section{Performance decrements in middle-aged swimmers}

Inauguration of the Masters Swimming program permitted, for the first time, a study of performance in older swimmers and its comparison to known aspects of power decrements with aging. ${ }^{4,5}$ Competition swim times were recorded, starting with the inaugural meet in Amarillo, and continue today. During the early years, comparatively few persons over age 60 competed, so that the first study of performance, by Rahe and Arthur ${ }^{6}$ using 1971-1973 data, considered first-place times for each five-year age group (25-29 years through 55-59 years). For all freestyle events (100, 200, 500 , and 1650 yards), there was a performance decrement of approximately $0.8 \%$ per year. Men swimming the 100 yard freestyle, backstroke, breaststroke and butterfly events showed decrements of $0.8 \%, 1 \%, 1 \%$, and $1.5 \%$ per year, respectively, indicating the greater difficulty of the butterfly compared to the other three strokes. Women swimming these four stroke events showed decrements of $1.2 \%, 1.2 \%, 1.4 \%$, and $1.8 \%$ per year, which were greater than those of the men, but the relatively fewer women swimmers make their data less accurate.

\section{Performance decrements in elderly swimmers}

There was an approximately 20-year hiatus between the early studies, conducted by Dr Ransom Arthur and his US Navy medical colleagues and teammates, and further studies of performance in these athletes. By the mid-1990s thousands of swimmers were participating, and the age groups had increased to include persons aged 90+. Bortz and Bortz ${ }^{7}$ compared Masters age records for three endurance events (marathon, 1500-meter swim, 1500-meter rowing), the 100 -meter dash, and the decline in maximal oxygen consumption $\left(\mathrm{VO}_{2 \max }\right.$; using data of Kasch and colleagues $\left.{ }^{8}\right)$, normed to age 35 for each of the four events. From age 35 to age 60 , the average performance decrement for each event was approximately $0.5 \%$ per year, with an acceleration between ages 65 and $80-85$, during which the endurance events showed greater declines than the sprints. $\mathrm{VO}_{2 \max }$ also decreased about $0.5 \%$ per year, similar to the findings of others. ${ }^{9,10}$ Bortz and Bortz ${ }^{7}$ commented on the cross-sectional nature of their swimming data (from 1992 records), and they did not indicate sample sizes or present separate data for men and women.

As the Masters Swimming program has grown, more recent studies have included subjects up to age 99. There still are, however, comparatively few elderly Masters swimmers, and data sets covering several years of swimming can include the same subjects at different ages as they move from one age group to the next ("aging up"). Tanaka and Seals ${ }^{11}$ performed a retrospective analysis of top US Masters freestyle times for the years 1991-1995 for a sprint event (50-meter freestyle) and an endurance event (1500-meter freestyle). Participants were divided into five-year age groups between 19 and 99 years (note that Masters Swimming now includes an 18- to 24-year age group), and the top 10 times within each age group were plotted against age separately for men and women. In addition, the 1995 records for the remaining freestyle events (100, 200, 400, 800 meters) were analyzed for men and women, to examine top times across the continuum of distances for that stroke.

Figure 1 presents the data for the 1500-meter and 50 -meter freestyle events. Consistent with the few earlier reports noted above, after the age of 40 in the men and age 35 in the women, swimming times increased approximately linearly until approximately age 70, after which times increased exponentially, more so for the women than for the men. The variability in times also increased with advancing age, especially after age 70 . Tanaka and Seals ${ }^{11}$ also noted 

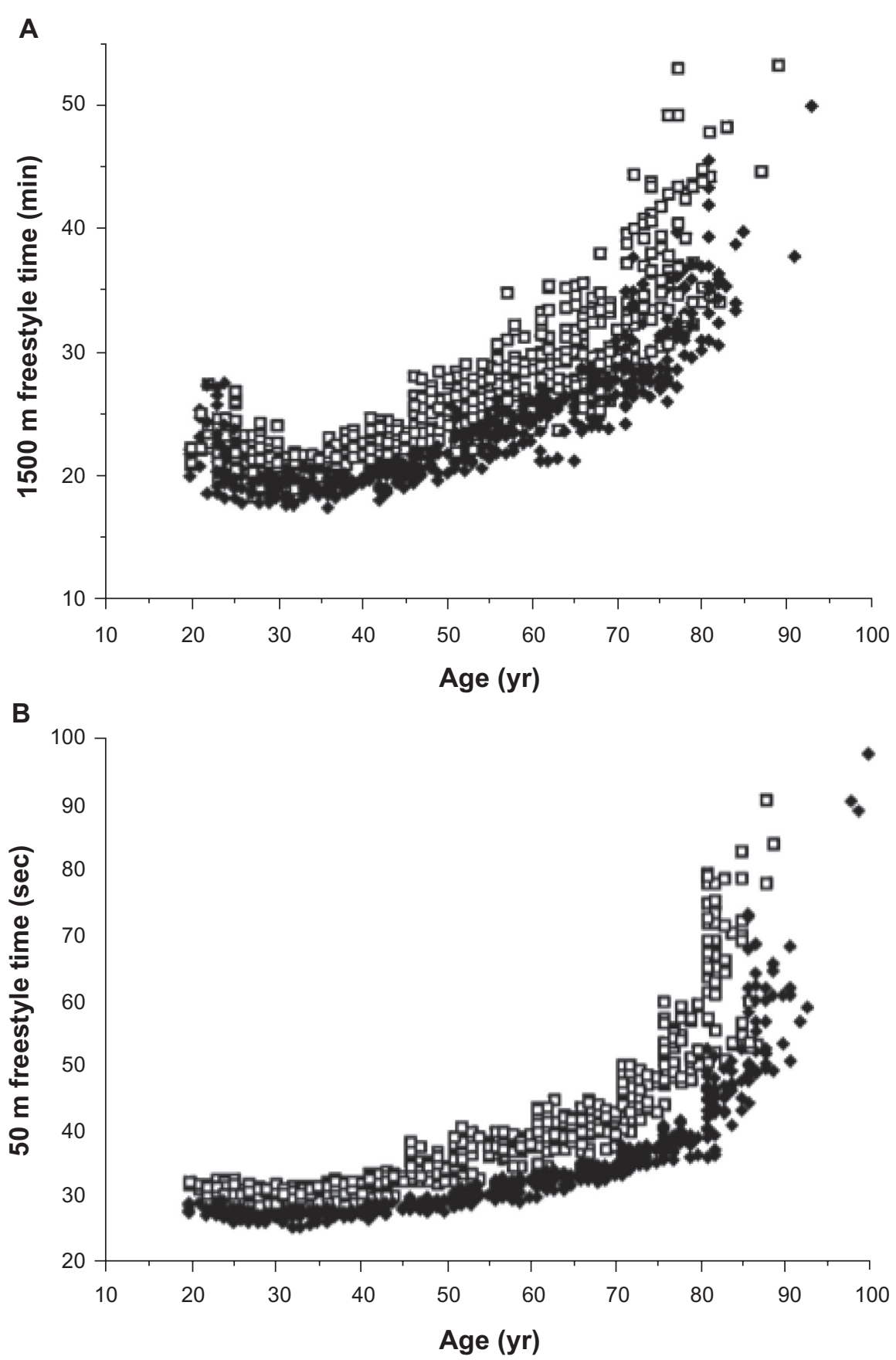

Figure I Age-related increases in US Masters Swimming championship times in the 1500-meter freestyle (A, top) and 50-meter freestyle (B, bottom) events for the years 1991-1995.

Notes: Open squares $=$ women; filled diamonds $=$ men. Reproduced with permission from Tanaka H, Seals DR.Age and gender interactions in physiological functional capacity: insight from swimming performance. J Appl Physiol. 1997;82(3):846-851." Courtesy of the American Physiological Society.

that reduced physiological functional capacity (the ability to perform the physical tasks of daily life) with advancing age is related to the totality of declining cardiovascular, respiratory, metabolic, and neuromuscular functions and emphasized, as have others, ${ }^{9,10}$ that $\mathrm{VO}_{2 \max }$ is one of the best single indicators of declining physiological functional capacity, because it sets the upper limit on maximal oxidative energy production. (Other potential contributing factors to performance decline in elderly Masters swimmers are discussed below).

Fair $^{12}$ mathematically modeled age decrements in several swimming and running events, and in chess as a measure of executive brain function. The decrement in chess occurred at a considerably slower rate than the decrements in physical 
performance. For the swimming measures, world records were obtained from US Masters Swimming for long course meters (17 events) and short course yards (18 events) for men and women by yearly ages through age 100. Data for all four events (freestyle, backstroke, breaststroke, and butterfly) were combined for three distances (50 meters, 100 meters, 200+ meters) for men and women separately; each of the six combined data sets contained between 231 and 574 observations. Unit-free, percent rates of decline were analyzed by a flexible functional form that assumed a linear rate of decline between age 35 (baseline) and a transition age that was estimated; beyond the transition age, a quadratic rate of decline was assumed.

For men, the rate of performance decrement was linear at $0.4 \%-1.0 \%$ per year (the smallest was for the 50 meter sprint distance) through age 70, with an accelerating decline in performance thereafter; by age 90 it was $3.2 \%-5 \%$ per year. For women, the linear decrement was similar at $0.5 \%-1.0 \%$ per year to age 60 , with an accelerating decline thereafter. Estimates of the rate of decline for both men and women above age 90 were less reliable, because of small sample sizes.

The above analyses ${ }^{7,11,12}$ were on primarily cross-sectional data, although some participants may have "aged up" (entered the next older age group) during the years of study and would have been counted more than once. To ascertain the decline in physiological functional capacity with age in a longitudinal sample, Donato and colleagues ${ }^{13}$ followed the performance times of 321 participants in US Masters Swimming championships within an overall 12-year period, 1988-1999. All had placed in the top 10 for their age groups over at least three years, the minimum number of years of participation needed to be included in the data set. The median length of time swimmers were followed was four years. For the 50-meter freestyle, 168 women's and 164 men's times were tabulated, and for the 1500-meter freestyle, 153 women's times and 155 men's times were tabulated. Ages ranged between 19 and 85 years.

Results were similar to those in the cross-sectional studies. ${ }^{7,11,12}$ Peak performance times were consistent until about age 35 , followed by a relatively linear increase to about age 70 , with an exponential increase in times thereafter. Performance decrements were greater in both sexes for the 1500-meter endurance event than for the 50-meter sprint. For the 1500-meter endurance swim the performance decrements were similar in men and women, but for the 50-meter sprint the decrement was significantly greater in the women than in the men. As with the cross-sectional studies, the variability in times in both sexes increased with advancing age. Donato and colleagues ${ }^{13}$ indicated that $\mathrm{VO}_{2 \max }$ contributes importantly to performance in endurance events, the age-related decline in $\mathrm{VO}_{2 \max }$ being a reasonable explanation for the similar age-related decrements in endurance-swim performance between men and women. In contrast, a major determinant of sprint performance is the anaerobic power of the upper body muscles, and a greater age-related decline in upper body strength in women could be an explanation for the greater decrement in sprint performance in the older female swimmers.

The inauguration of Masters one-hour swims for distance has afforded additional data on performance decrements with aging. Bongard and colleagues ${ }^{14}$ studied 4,271 "presumably healthy" men and women, ages 19-91 years, participating in the 2001-2003 one hour national swimming competitions. The variability in distance at each age was considerably greater than the variability in times for the shorter distance swims reported above, perhaps owing to the more recent introduction of the one-hour swim in the competition repertoire and the relative lack of training for this event. Nevertheless, the mean performance decrements were quite similar to those found with the shorter distance events; ie, reasonably linear between ages 19 and 70 at about $0.6 \%$ per year for men and $0.7 \%$ for women, and accelerating after age 70 to about $1.5 \%$ per year for men and $1.6 \%$ per year for women. Thus, the effects of physiological aging on competitive swimmers appear to be consistent for all distances, from a 50-meter sprint to a several-thousand-meter swim over an hour, and these effects appear to accelerate after age 70, resulting in a steeper decline of performance in the very elderly. The linear decrement of $0.6 \%-0.7 \%$ per year up to age 70 has been confirmed across 13 physiological systems in hundreds of studies $($ mean $=0.65 \%$; median $=0.5 \%$ per year $),{ }^{15}$ but there are few confirmatory data for individuals age $70+$.

As mentioned above, the greater the number of years included in a cross-sectional study, the greater the possibility of a given athlete's being included in more than one age group (aging up), a factor that may bias the findings of these studies. Fairbrother ${ }^{16}$ assessed whether age representation influenced predicted All-American Masters 1500-meter freestyle swimming times by determining age-related performance decrements using data from all swimmers, ages 19-99, for the years 1993-2001 versus data from just the swimmers $>70$ years of age during those nine years. Until about age 83 , the predictions from the all-ages data were similar to the predictions from the older-ages data, whereas after age 83, the older-ages data provided a more accurate prediction of performance decrement. Fairbrother ${ }^{16}$ concluded that the 
increase in age-related rate of change after age 70 was not due to disproportionate sampling across age groups but reflected a real difference in the factors influencing performance in the younger and older swimmers. Thus, in Masters athletes (swimmers and runners), peak performance is maintained until about age 35 , with a linear decrease of $0.6 \%-0.7 \%$ until about age 70 , followed by an exponential performance decline thereafter. ${ }^{17}$ The primary physiological mechanism is a progressive decrease in $\mathrm{VO}_{2 \max }$, to which decreases in maximal cardiac stroke volume, heart rate, and arteriovenous $\mathrm{O}_{2}$ differences contribute. ${ }^{18}$

In addition to this systematic effect of accelerated physiological aging, several factors specific to Masters Swimming may be related to the lesser number of swimmers and their exponential performance decline after age 70. Although swimming is a relatively benign stressor of the musculoskeletal system, orthopedic injuries can occur when certain strokes are performed strenuously over several decades, and both shoulder and knee replacements have been needed in long-duration Masters swimmers due to excessive thinning of joint cartilage. As well, acute rotator cuff tears are not uncommon, and rare orthopedic injuries have occurred, such as an Achilles tendon tear when one older swimmer jumped feet first into the deep end of the pool.

Older swimmers also may have balance problems that prevent them from diving from a starting block; some dive from the edge of the pool, and others need to start from a push-off within the pool. These alternative starting methods can add several seconds to performance time. Balance problems also can prevent older swimmers from doing flip turns during freestyle and backstroke races, again adding to performance times.

There are, of course, many general physical issues that impact the elderly. In addition to musculoskeletal problems, other chronic physical disabilities accumulate over time, including hypertension, vascular disease, type II diabetes, and a slow decrease in brain size and function. ${ }^{19}$ Implanted cardiac pacemakers can limit maximal cardiac response to strenuous exercise. The comfortable water environment may mask angina in persons with ischemic heart disease, ${ }^{20}$ and myocardial, as well as cerebrovascular, infarctions have occurred in older swimmers during workouts and competitions. Acute intercurrent illnesses often require a lengthy recovery. Implanted artificial joints can be painful for extended periods and limit range of motion. The effects of multiple medications for control of blood pressure, glucose, lipids, etc. also can adversely impact exercise tolerance; eg, statins for control of circulating lipids are in widespread use in the elderly, and their adverse effects on muscle can be exacerbated by strenuous exercise. ${ }^{21}$ Finally, social issues such as transportation problems also can lead to increasing difficulty in maintaining an intensive and regular workout schedule.

\section{Achieving optimal health benefits in elderly swimmers}

From its inception, a major focus of Masters Swimming has been to promote healthy exercise. As competitors have increased and improved their swim training, many have lost excess body fat, increased limb and trunk muscle strength, and sometimes experienced a reduction of elevated blood pressure. As their best swim times decreased, they often have said that they felt younger. Some swimmers began to achieve faster times than when they had been competing in college. Fairbrother ${ }^{16}$ commented that the estimated 1500 meter times for the 75- to 83-year-olds in his study, between 27 and 33 minutes, were quite impressive, given that the US Navy considers an excellent young swimmer to be someone who can swim 450 meters at a pace equivalent to 29 minutes for 1500 meters.

The early hope that Masters Swimming was somehow reversing the aging process quickly gave way to an evidencebased understanding of its real effects, as noted above. In reality, most Masters swimmers were moving from the $\sim 0.6 \%$ per year decline in performance for a relatively untrained swimmer to the $\sim 0.6 \%$ per year decline of a highly trained swimmer; ie, they were starting from a higher baseline. ${ }^{17}$ That statistical message was brought home to individual participants: new to Masters Swimming, having improved their times for a few years with long and strenuous workouts, and thereby having reached the performance level of a highly trained swimmer, they saw their best times increasing "at a stately pace" 22 yet again as the ensuing years went by.

Unfortunately, the early enthusiasm of Masters swimmers, frequently leading to more and more training, was not promoting healthy exercise. Swimmers in the pool three to four hours a day, six to seven days per week, were overstressing themselves physically as well as missing important time with their families and previously attended social and community activities. A significant blow for many early Masters champions occurred when former Olympic Games competitors began to join the program: No amount of swim training could match the skills and long-term fitness of these gifted athletes. Clarence "Buster" Crabbe, for example, an Olympic gold medalist who played and swam as Tarzan in the movies, joined Masters Swimming national competition 
in 1972 as an extremely fit 64-year-old with a classic and swift freestyle stroke.

These early issues notwithstanding, 35 years after Ransom Arthur proposed Masters Swimming as a lifetime antidote to the high prevalence of cardiovascular disease in North America and Western Europe, ${ }^{23}$ tens of thousands of participants, including centenarians, use Masters Swimming as a "motivating force for the continuance of a regular training program of a healthful nature." ${ }^{23}$ Masters Swimming is a "user-friendly" aerobic sport, imposing little excess strain, and thus is particularly suitable for the elderly. Being in a formal training environment such as belonging to a Masters club forces involvement in higher-intensity aerobic workouts, which are more effective in augmenting and maintaining $\mathrm{VO}_{2 \max }$ than is low to moderate intensity aerobic exercise. ${ }^{17}$ As more and more elderly swimmers participate, Masters coaches are gaining increasing experience with these age groups, tailoring workouts to accommodate their need for longer warm-up periods, longer rest periods between swimming sets, less overall distance, less emphasis on breath control (breathing every 3, 5, 7, or so strokes, which demands enhanced $\mathrm{O}_{2}$ extraction from blood $^{24}$ ), and more time between workouts, as well as including dry-land stretching exercises to maintain flexibility. Many Masters swimmers train on their own, without supervision from a knowledgeable coach, and the training adjustments for optimal health mentioned above need to reach these individuals. With the aforementioned accommodations, the motivation of elderly Masters swimmers to train and compete will remain strong, and their ranks should continue to increase.

\section{Acknowledgements/Disclosures}

David Ciraulo, MD, and an anonymous reviewer provided important references for inclusion.

The authors declare no conflicts of interest.

\section{References}

1. Stott MJ. Masters nationals turn 30. (http://www.usms.org/swimgold/ hist/history.htm) Accessed February 2010.

2. US Masters Swimming (www.usms.org). Accessed February 2010.

3. Zir LM, Rahe RH, Rubin RT, Arthur RJ. Effects of strenuous swim competition in the older age group. $J$ Sports Med Physical Fitness. 1972;12(3):180-185.
4. Pollock ML, Mengelkoch LJ, Graves JE, and colleagues. Twenty-year follow-up of aerobic power and body composition of older track athletes. J Appl Physiol. 1997;82(5):1508-1516.

5. Joyner MJ. Physiological limiting factors and distance running: influence of gender and age on record performances. Exerc Sport Sci Rev. 1993;21:103-133.

6. Rahe RH, Arthur RJ. Swim performance decrement over middle life. Med Sci Sports. 1975;7(1):53-58.

7. Bortz WM 4th, Bortz WM 2nd. How fast do we age? Exercise performance over time as a biomarker. J Gerontol: Med Sci. 1996;51A(5): M223-M225.

8. Kasch FW, Boyer H, van Camp SP, Verity LS, Wallace SP. The effect of physical activity and inactivity on aerobic power in older men (a longitudinal study). J Physician Sports Med. 1990;18:73-83.

9. Pollock ML, Foster C, Knapp D, Rod JL, Schmidt DH. Effect of age and training on aerobic capacity and body composition of master athletes. J Appl Physiol. 1987;62(2):725-731.

10. Rogers MA, Hagberg JM, Martin WH 3rd, Ehsani AA, Holloszy JO. Decline in $\mathrm{VO}_{2}$ max with aging in master athletes and sedentary men. J Appl Physiol. 1990;68(5):2195-2199.

11. Tanaka H, Seals DR. Age and gender interactions in physiological functional capacity: insight from swimming performance. J Appl Physiol. 1997;82(3):846-851.

12. Fair RC. Estimated age effects in athletic events and chess. Exp Aging Res. 2007;33:37-57.

13. Donato AJ, Tench K, Glueck DH, Seals DR, Eskurza I, Tanaka H. Declines in physiological functional capacity with age: a longitudinal study in peak swimming performance. J Appl Physiol. 2003;94:764-769.

14. Bongard V, McDermott AY, Dallal GE, Schaefer EJ. Effects of age and gender on physical performance. Age. 2007;29:77-85.

15. Sehl ME, Yates FE. Kinetics of human aging: I. Rates of senescence between ages 30 and 70 years in healthy people. J Gerontol Biol Sci. 2001;56A(5):B198-B208.

16. Fairbrother JT. Prediction of 1500-m freestyle swimming times for older Masters All-American swimmers. Exp Aging Res. 2007;33:461-471.

17. Tanaka H, Seals DR. Dynamic exercise performance in Masters athletes: insight into the effects of primary human aging on physiological functional capacity. J Appl Physiol. 2003;95(11):2152-2162.

18. Tanaka H, Seals DR. Endurance exercise performance in Masters athletes: age-associated changes and underlying physiological mechanisms. J Physiol. 2008;586(1):55-63.

19. Fjell AM, Walhovd KB, Fennema-Notestine C, and colleagues. One-year brain atrophy in healthy aging. $J$ Neurosci. 2009;29(48): 15223-15231.

20. Magder S, Linnarsson D, Gullstrand L. The effect of swimming on patients with ischemic heart disease. Circulation 1981;63(5): 979-986.

21. Sinzinger H, O'Grady J. Professional athletes suffering from familial hypercholesterolaemia rarely tolerate statin treatment because of muscular problems. Brit J Clin Pharmacol. 2004;57(4):525-528.

22. Bortz WM II. Nonage versus age. J Gerontol: Med Sci. 2001;56A(9): M527-M528.

23. Arthur RJ. Swimming and cardiovascular fitness in the older age group. J Sports Med. 1975;3(1):35-40.

24. Town GP, Vanness JM. Metabolic responses to controlled frequency breathing in competitive swimmers. Med Sci Sports Exerc. 1990;22(1):112-116.

Open Access Journal of Sports Medicine

\section{Publish your work in this journal}

Open Access Journal of Sports Medicine is an international, peer-reviewed, open access journal publishing original research, reports, reviews and commentaries on all areas of sports medicine. The manuscript management system is completely online and includes a very quick and fair peer-review system.

Submit your manuscript here: http://www.dovepress.com/open-access-journal-of-sports-medicine-journal

\section{Dovepress}

Visit http://www.dovepress.com/testimonials.php to read real quotes from published authors. 